\title{
Effects of Pimenta pseudocaryophyllus extracts on gout: Anti- inflammatory activity and anti-hyperuricemic effect through xantine oxidase and uricosuric action
}

\author{
Fernanda Cristina Ferrari, Rita de Cássia Lemos Lima, Zilma Schimith Ferraz Filha, \\ Camila Helena Barros, Marcela Carolina de Paula Michel Araújo, \\ Dênia Antunes Saúde-Guimarães* \\ Laboratório de Plantas Medicinais, Escola de Farmácia, Universidade Federal de Ouro Preto, Ouro Preto, Minas Gerais 35400-000, Brazil
}

\section{A R T I C L E I N F O}

\section{Article history:}

Received 7 October 2015

Received in revised form

31 December 2015

Accepted 7 January 2016

Available online 8 January 2016

Keywords:

Pimenta pseudocaryophyllus

Hyperuricemia

Xanthine oxidase

Uricosuric

Inflammation

Gout

\begin{abstract}
A B S T R A C T
Ethnopharmacological relevance: Leaves infusion of Pimenta pseudocaryophyllus (Gomes) Landrum is used in Brazilian folk medicine to treat the predisposition to arthritical and gouty affections of the joints, fever and other diseases. A refreshing drink prepared with the specie is also used due to its diuretic, sedative and aphrodisiac actions.

Aim of the study: The study was undertaken to investigate the mechanisms of anti-hyperuricemic effect and anti-inflammatory activity of $P$. pseudocaryophyllus extracts.

Materials and methods: Anti-hyperuricemic effect was investigated using xanthine oxidase assay and uricosuric studies with rats in which hyperuricemia was induced by potassium oxonate and uric acid. Anti-inflammatory activity was investigated on MSU crystal-induced paw edema model. Ethyl acetate extracts of the leaves (EAL) and branches (EAB), ethanolic extracts of leaves (EEL) and branches (EEB) and aqueous extracts of leaves $(\mathrm{AL})$ and branches $(\mathrm{AB})$ were evaluated.

Results: The extracts of $P$. pseudocaryophyllus evaluated showed expressive results regarding the inhibition of xanthine oxidase enzyme in vitro and they were also able to reduce serum uric acid levels in hyperuricemic rats. The investigation of the mechanism of action, it was found that EAL, EAB, EEB, AB (125 and $250 \mathrm{mg} / \mathrm{kg}$ ) and $\mathrm{AL}(250 \mathrm{mg} / \mathrm{kg})$ promoted an increase on the urinary excretion of uric acid and EEL, EEB, AB (125 and $250 \mathrm{mg} / \mathrm{kg})$ and EAB $(250 \mathrm{mg} / \mathrm{kg})$ were capable to inhibit liver xanthine oxidase. Treatments with EEL (125 and $250 \mathrm{mg} / \mathrm{kg})$ and EEB (250 mg/kg) were able to reduce edema at 48 th $\mathrm{h}$. EAL and EAB (125 and $250 \mathrm{mg} / \mathrm{kg}$ ) showed significant anti-inflammatory activity on monosodium urate crystal-induced paw edema model at all evaluated times.

Conclusions: The specie $P$. pseudocaryophyllus showed remarkable anti-hyperuricemic effects through uricosuric effects and inhibition of xanthine oxidase and therefore can be considered as a promise in the treatment of diseases related to hyperuricemia. Moreover, ethyl acetate extracts had significant antiinflammatory activity.
\end{abstract}

(c) 2016 Elsevier Ireland Ltd. All rights reserved.

\section{Introduction}

Hyperuricemia is a pathological condition involved in a disease known as gout, which is characterized by a painful inflammatory arthritis induced by deposition of sodium urate crystals (uric acid) in the joints, synovial fluid and other tissues (Albrecht et al., 2014). High levels of uric acid in the body may result from the deficiency on excretion of this substance or by increased production. The

\footnotetext{
* Corresponding author.

E-mail addresses: saude@ef.ufop.br, saudeguima@gmail.com (D. Antunes Saúde-Guimarães).

development of the disease is related to factors such as gender, age, ethnicity and lifestyle, affecting mainly middle-aged men (Pinheiro, 2008).

The gout initial therapy is performed with drugs such as colchicine, nonsteroidal anti-inflammatory (NSAIDs) and oral corticosteroids. In addition, there are drugs that act on the hyperuricemia development process. Some of them can reduce the endogenous production of uric acid, as allopurinol. Others like probenecid and benzbromarone increase uric acid elimination and are called uricosuric agents, useful in underexcreters patients. However, these drugs have been associated with adverse effects including renal and gastrointestinal toxicity (Miguel and Mediavilla, 2011). 
Pimenta pseudocaryophyllus (Gomes) Landrum, popularly known as "cataia", "craveiro" or "louro-cravo" is a specie from Myrtaceae family largely distributed in pantropical and subtropical regions (Fajemiroye et al., 2012; Paula et al., 2012). In folk medicine, the leaves of $P$. pseudocaryophyllus are used to prepare a refreshing drink known for its diuretic, sedative and aphrodisiac actions (Paula et al., 2012). The population of Guaraqueçaba, state of Paraná, Brazil, uses P. pseudocaryophyllus leaves infusion in the form of tea to treat the predisposition to arthritical and gouty affections of the joints, fever and other diseases (D'Angelis and Negrelle, 2014).

Previous studies about $P$. pseudocaryophyllus described its anxiolytic and sedative action (Fajemiroye et al., 2012) and antioxidant activity (Campanini et al., 2014).

In the present study, it was reported that $P$. pseudocaryophyllus extracts are capable to reduce serum uric acid levels in hyperuricemic rats. Thus, the mechanisms on which the substances contained in the specie extracts exert the anti-hyperuricemic effect were investigated. In a complementary way, the anti-inflammatory activity was also evaluated through an experimental model of gouty arthritis induced by monosodium urate (MSU) crystals.

\section{Materials and methods}

\subsection{Chemicals and reagents}

Xanthine, potassium oxonate, uric acid, probenecid, benzbromarone, allopurinol and indomethacin were purchased from Sigma-Aldrich (USA). Ketamine and xylasine was obtained from Sespro Industria e Comercio Ltda (Brazil). Uric acid assay kit was purchased from Bioclin (Brazil). Monosodium urate (MSU) crystals were prepared according to previously described method (Rasool and Varalakshmi, 2006). All other chemicals were the highest analytic grade available.

\subsection{Plant material}

Leaves and branches from P. pseudocaryophyllus (Gomes) Landrum were collected in Lagoa Santa, Minas Gerais, Brazil, in October 2012. Coordinates of the location of the plant: 19'32' $49.16^{\prime \prime} \mathrm{S} / 43^{\circ} 54^{\prime} 30.39^{\prime \prime} \mathrm{O}$. Voucher specimens were deposited in the Herbarium of Instituto de Ciências Exatas e Biológicas - UFOP, Ouro Preto, Brazil, reference number (OUPR 25900). Plant specie was collected with permission of Instituto Chico Mendes de Conservação da Biodiversidade - ICMBio/Sistema de Autorização e Informação em Biodiversidade-SISBIO (license No. 17021-8). The plant botanical identification was realized by Dr. Marcos Eduardo Guerra Sobral, Departamento de Ciências Naturais, Universidade Federal de São João Del-Rei (UFSJ).

\subsection{Preparation of plant extracts}

Leaves and branches were air-dried and pulverized separately. Extraction of leaves (1742.0 g) and branches (2896.0 g) was carried out by percolation method using hexane, ethyl acetate and ethanol in order of increasing polarity until exhaustion. Solvents were removed under reduced pressure at $40{ }^{\circ} \mathrm{C}$ using a rotatory evaporator (Buchi), yielded the following dry extracts: hexanic leaves (HL, $30.0 \mathrm{~g}$ ), hexanic branches (HB, $3.8 \mathrm{~g}$ ), ethyl acetate leaves (EAL, $74.0 \mathrm{~g}$ ), ethyl acetate branches (EAB, $50.0 \mathrm{~g}$ ), ethanolic leaves (EEL, $236.0 \mathrm{~g}$ ) and ethanolic branches (EEB, $182.0 \mathrm{~g}$ ). The aqueous extracts were obtained by exhaustive percolation of $70.0 \mathrm{~g}$ of leaves and branches powder with distillated water. The water was removed by lyophilization, yielding $9.6 \mathrm{~g}$ of aqueous crude extract of leaves $(\mathrm{AL})$ and $4.9 \mathrm{~g}$ of aqueous crude extract of branches ( $\mathrm{AB})$.

\subsection{Preliminary phytochemical screening}

The presence of tannins and polyphenols, flavonoids, glycosides and aglycones anthraquinones, triterpenes, steroids, coumarins, alkaloids, saponins, glycosides cardiotonic, and proanthocyanidins were evaluated in the extracts of $P$. pseudocaryophyllus. Analyses were performed using the standard procedure previously described (Farnsworth, 1966; Matos, 1997). Triterpenes and steroids were analyzed using Lieberman-Burchard reaction. The presence of saponins was evaluated using froth test. Coumarins, quinones and anthraquinones were researched in the extracts using alkali reaction. Presence of alkaloids was evaluated by the Dragendorff reaction. Tannins were analyzed using ferric trichloride and potassium ferrocyanide. Flavonoids were detected by hydrochloric acid-magnesium reaction and TLC sprayed with NP/PEG reagent. Anthocyanins and catechins were assayed using hydrochloric acid and sodium hydroxide.

\subsection{In vitro xanthine oxidase assay}

The assay with P. pseudocaryophyllus extracts was carried out using a previous methodology described by Ferraz Filha et al. (2006), with modifications. EAL, EAB, EEL and EEB were solubilized in distilled water and DMSO (1\%) to give final concentrations of $10.0 ; 20.0 ; 30.0 ; 40.0 ; 50.0$ and $100.0 \mu \mathrm{g} / \mathrm{mL}$, in order to obtain the $\mathrm{IC}_{50}$ values. In a bucket containing a volume of $500 \mu \mathrm{L}$ of each sample was added $1.125 \mathrm{~mL}$ of phosphate buffer ( $\mathrm{pH} 7.4)$ and $187.5 \mu \mathrm{L}$ XO enzyme $(0.28 \mathrm{U} / \mathrm{mL})$. This system was incubated at $30{ }^{\circ} \mathrm{C}$ for $10 \mathrm{~min}$. After that, $1.375 \mathrm{~mL}$ of xanthine substrate was added and immediately absorbances were obtained every minute for $10 \mathrm{~min}$ at $295 \mathrm{~nm}$ (Varian BIO-50). Allopurinol, a xanthine oxidase inhibitor, was used as positive control $(10 \mu \mathrm{g} / \mathrm{mL})$. The results were expressed as percentage of XO inhibition and calculated as: $\%$ inhibition $=(1-$ test inclination/blank inclination $) \times$ 100.

\subsection{Animals}

Male albino Swiss mice (25-30 g) and male Wistar rats (180$280 \mathrm{~g}$ ) were supplied by Universidade Federal de Ouro Preto and all the experimental procedures were approved by its Ethical Committee under registration numbers: 2012/66 and 2014/31. Animals were divided into experimental groups $(n=6)$, housed in plastic boxes and maintained on a 12-h light/12-h dark cycle, at room temperature of $25^{\circ} \mathrm{C}$. They were given standard chow and water ad libitum. Experimental procedures were performed in accordance to the Guide for the Care and Use of Laboratory Animals, published by the US National Institute of Health (NIH Publication, revised in 1985).

\subsection{Uricosuric activity in rats}

Murugaiyah and Chan (2009) previously described the animal model used in the anti-hyperuricemic study. Rats received potassium oxonate $(200 \mathrm{mg} / \mathrm{kg}$, intraperitoneal) and uric acid $(1 \mathrm{~g} / \mathrm{kg}$, by gavage) to become hyperuricemic. Food and water were withdrawn overnight prior to the study. EAL, EAB, EEL and EEB (125 and $250 \mathrm{mg} / \mathrm{kg}$ ) were prepared in $5 \%$ DMSO oil solution and the clinically used drugs, benzbromarone $(10 \mathrm{mg} / \mathrm{kg})$ and probenecid $(50 \mathrm{mg} / \mathrm{kg}$ ) were prepared in a mixture of $10 \%$ ethanol in $20 \%$ Tween 20 aqueous solution. The formulations were administered intraperitoneally to the rats $30 \mathrm{~min}$ after hyperuricemia induction. For normal and hyperuricemic controls, the animals were treated only with the vehicle. Then, the animals were placed in metabolic 
cages with $100 \mathrm{~mL}$ of tap water. The urine collected in graduated tubes and the water intake were measured for $5 \mathrm{~h}$ after the treatments. Finally, the animals were anesthetized with an association of ketamine and xylasine ( 40 and $87 \mathrm{mg} / \mathrm{kg}$, respectively), administered intraperitoneally, in order to collect the blood from abdominal aorta. Blood samples were maintained at room temperature until blood coagulation and, afterwards, the serum was obtained after centrifugation at $3000 \mathrm{~g}$ for $10 \mathrm{~min}$. The serum and urine samples were stored at $-20^{\circ} \mathrm{C}$ until uric acid quantification, which was performed by colorimetric method, using a standard diagnostic kit (Bioclin, Brazil), according to manufacturer's instructions.

\subsection{In vivo xanthine oxidase assay}

Rat's livers were excised immediately after blood collection, washed in $0.9 \%$ saline and rapidly stored at $-80{ }^{\circ} \mathrm{C}$ until processing. One group of animals was treated with allopurinol $(10 \mathrm{mg} /$ $\mathrm{kg}$ ), known xanthine oxidase inhibitor, for positive control of this assay. The separation of cytosolic fraction containing the enzyme was performed as described elsewhere (Haidari et al., 2009; Zhu et al., 2004). Briefly, livers were homogenized in $5 \mathrm{~mL}$ of $80 \mathrm{mM}$ sodium phosphate buffer ( $\mathrm{pH} 7.4$ ). The homogenate was centrifuged at $3000 \mathrm{~g}$ for $10 \mathrm{~min}$ at $4{ }^{\circ} \mathrm{C}$. The lipid layer was removed and the supernatant was centrifuged again at 10,000g for $60 \mathrm{~min}$ at $4{ }^{\circ} \mathrm{C}$, resulting in the cytosolic fraction. This fraction was used to evaluate liver xanthine oxidase residual activity according to a method previously described by Hall et al. (1990) with modifications. The formation of uric acid was monitored spectrophotometrically. Briefly, $100 \mu \mathrm{L}$ of the liver cytosolic fraction was pre-incubated in $5.4 \mathrm{~mL}$ of potassium oxonate solution $(1 \mathrm{mM})$ in $50 \mathrm{mM}$ sodium phosphate buffer ( $\mathrm{pH} 7.4$ ) at $35^{\circ} \mathrm{C}$ for $15 \mathrm{~min}$. After the incubation period, $1.2 \mathrm{~mL}$ of xanthine solution $(250 \mathrm{mM})$ was added to start the reaction, which, in turn, was stopped after 0 and 30 min by the addition of $500 \mu \mathrm{L}$ of $0.6 \mathrm{M} \mathrm{HCl}$. The samples were centrifuged at $3000 \mathrm{~g}$ for $5 \mathrm{~min}$ and the uric acid in the supernatant was spectrophotometrically quantified at $295 \mathrm{~nm}$ (Varian BIO-50). Protein concentration was determined according Bradford (1976) method using bovine serum albumin as standard. Enzyme activity was expressed as nmoles of uric acid produced per min by $1 \mathrm{mg}$ of protein $[\mathrm{nmol} /(\min \mathrm{mg}$ protein $)]$.

\subsection{Effects on monosodium urate crystal-induced inflammation in mice}

Anti-inflammatory activity of $P$. pseudocaryophyllus extracts was evaluated using an animal model of paw edema adapted from the previously described method by Rasool and Varalakshmi (2006). On the first day of the experiment (time 0), the inflammation was induced by injection of $50 \mu \mathrm{L}(80 \mathrm{mg} / \mathrm{mL})$ of urate crystals suspension (MSU) into the subplantar region of the mouse right hind paw, while the normal control group received saline $0.9 \%$. EAL, EAB, EEL and EEB ( 125 and $250 \mathrm{mg} / \mathrm{kg}$ ) were prepared in $5 \%$ DMSO oily solution. Indomethacin $(3 \mathrm{mg} / \mathrm{kg}$ ) was prepared in a mixture of $10 \%$ Tween 20 aqueous solution. The samples were administered by gavage $1 \mathrm{~h}$ before MSU injection and repeated daily for 2 more days. For normal and inflammation controls, only vehicle was given to the animals. The paw thickness between the dorsal and ventral faces of the paws was obtained using a caliper rule at $0,4,24$ and $48 \mathrm{~h}$ after the MSU injection, while inflammatory swelling was expressed as thickness variation $(\Delta)$ versus time 0 .

\subsection{Statistical analysis}

The results were presented as mean \pm standard error of the mean (S.E.M.) of six animals. The statistical significance of the difference was evaluated by analysis of variance (ANOVA) followed by Dunnett's test using GraphPad Prism 5.0 Software (Inc., San Diego, CA, USA). The $\mathrm{IC}_{50}$ values were calculated by linear regression.

\section{Results}

Gout is an acute inflammatory arthritis caused by deposition of uric acid in the joints and tissues. About 10\% of individuals with hyperuricemia develop gout and $90 \%$ of gout patients have hyperuricemia (Smith et al., 2010). The therapeutic control of gout consists in the treatment of the acute inflammatory process and reduction of blood uric acid levels. Gout management is based on the use of anti-inflammatory drugs, xanthine oxidase inhibitors and consequently inhibition of uric acid synthesis and drugs that increase the excretion of uric acid. In the present study, in vitro and in vivo xanthine oxidase inhibitory activity, anti-hyperuricemic, uricosuric and anti-inflammatory effects of extracts from P. pseudocaryophyllus were evaluated.

\subsection{Screening of chemical compounds in the species}

In pharmacognostic analyses were detected the presences of triterpenes, steroids, coumarins, saponins, tannins and flavonoids. The positive reaction of EEL, EEB, AL and EB with sodium nitrite, indicated the presence of hydrolysable tannins and the negative reaction with $n$-butanol, suggested the absence of condensed tannins in these extracts. Chromatographic plate containing samples of these extracts revealed with sulfuric acid confirmed the absence of proanthocyanidins. In EAB and EEL were identified the presence of coumarins. Flavonoids were detected in EAL, EAB, EEL, EEB, AL and $A B$. In aqueous extracts ( $A L$ and $A B$ ) were identified the presence of saponins. Triterpenes and steroids were detected in EAL.

\subsection{In vitro xanthine oxidase inhibitory activity}

The inhibitory activity of $P$. pseudocaryophyllus extracts against xanthine oxidase and their respective $\mathrm{IC}_{50}$ values are shown in Table 1. Allopurinol, positive control for the bioassay, showed an $\mathrm{IC}_{50}$ of $0.33 \mu \mathrm{g} / \mathrm{mL}$. EAL, EAB and EEB showed $\mathrm{IC}_{50}$ values of 14.07 ; 15.57 and $13.73 \mu \mathrm{g} / \mathrm{mL}$, respectively.

\subsection{Anti-hyperuricemic effects of Pimenta pseudocaryophyllus ex- tracts in hyperuricemic rats}

Potassium oxonate solution significantly increased serum urate levels compared to normal control group (Table 2). Animals treated with extracts showed a reduction on serum uric acid levels, especially those animals treated with EAB $(250 \mathrm{mg} / \mathrm{kg})$. This

Table 1

In vitro inhibitory xanthine oxidase activity of extracts from Pimenta pseudocaryophyllus.

\begin{tabular}{lccc}
\hline Sample & Concentration $(\mu \mathrm{g} / \mathrm{mL})$ & Inhibition $(\%)$ & $\mathrm{IC}_{50}(\mu \mathrm{g} / \mathrm{mL} \pm$ S.D. $)$ \\
\hline Allopurinol & 10 & 95.63 & $0.33 \pm 0.011$ \\
EAL & 100 & 72.54 & $14.07 \pm 1.689$ \\
EEL & 100 & 76.47 & $19.91 \pm 1.859$ \\
AL & 100 & 45.94 & $109.7 \pm 3.926$ \\
EAB & 100 & 80.91 & $15.57 \pm 1.561$ \\
EEB & 100 & 81.63 & $13.72 \pm 1.167$ \\
AB & 100 & 57.05 & $54.65 \pm 1.300$
\end{tabular}

Ethyl acetate extract of leaves (EAL), ethanolic extract of leaves (EEL), aqueous extract of leaves $(A L)$, ethyl acetate extract of branches (EAB), ethanolic extract of branches (EEB) and aqueous extract of branches (AB). 
Table 2

Effects of Pimenta pseudocaryophyllus extracts on water intake, urine output, uric acid excretion and serum uric acid in hyperuricemic rats.

\begin{tabular}{|c|c|c|c|c|c|}
\hline Group & Dose (mg/kg) & Water intake $(\mathrm{mL})$ & Urine output (mL) & Uric acid excretion $(\mathrm{mg} /(\operatorname{kg} 5 \mathrm{~h}))$ & Serum uric acid (mg/dL) \\
\hline Normouricemic control & - & $6.78 \pm 1.051$ & $4.56 \pm 1.002$ & $1.20 \pm 0.292^{\mathrm{a}}$ & $0.83 \pm 0.094^{b}$ \\
\hline Hyperuriccemic control & - & $6.19 \pm 0.634$ & $7.87 \pm 0.638$ & $11.62 \pm 0.625^{c}$ & $8.67 \pm 0.629^{d}$ \\
\hline Benzbromarone & 10 & $6.00 \pm 0.578$ & $5.58 \pm 0.701$ & $19.47 \pm 0.745^{\mathrm{e}}$ & $2.88 \pm 0.320^{\mathrm{b}}$ \\
\hline Probenecid & 50 & $6.92 \pm 0.811$ & $6.58 \pm 0.908$ & $20.81 \pm 1.545^{\mathrm{a,c}}$ & $1.81 \pm 0.771^{\mathrm{b}}$ \\
\hline \multirow[t]{2}{*}{ EAL } & 125 & $7.67 \pm 0.919$ & $7.67 \pm 0.919$ & $22.13 \pm 3.000^{\mathrm{e}}$ & $4.74 \pm 0.853^{\mathrm{a}, \mathrm{f}}$ \\
\hline & 250 & $9.17 \pm 0.527$ & $8.50 \pm 1.384$ & $29.66 \pm 1.295^{\mathrm{b}, \mathrm{d}}$ & $4.38 \pm 0.899^{\mathrm{a}, \mathrm{f}}$ \\
\hline \multirow[t]{2}{*}{ EEL } & 125 & $7.67 \pm 0.645$ & $4.83 \pm 1.559$ & $6.68 \pm 0.424$ & $5.61 \pm 0.587^{\mathrm{d}, \mathrm{e}}$ \\
\hline & 250 & $6.83 \pm 0.694$ & $3.83 \pm 1.120$ & $12.10 \pm 0.639$ & $5.01 \pm 0.359^{\mathrm{a}, \mathrm{d}}$ \\
\hline \multirow[t]{2}{*}{$\mathrm{AL}$} & 125 & $4.89 \pm 0.611$ & $4.89 \pm 1.169$ & $5.32 \pm 0.599$ & $3.87 \pm 0.373^{\mathrm{b}, \mathrm{f}}$ \\
\hline & 250 & $5.89 \pm 0.772$ & $5.78 \pm 1.245$ & $22.31 \pm 1.528^{\mathrm{a}, \mathrm{c}}$ & $4.32 \pm 0.765^{\mathrm{b}, \mathrm{f}}$ \\
\hline \multirow[t]{2}{*}{ EAB } & 125 & $8.40 \pm 0812$ & $6.33 \pm 1.229$ & $27.27 \pm 0.808^{\mathrm{b}, \mathrm{d}}$ & $4.72 \pm 0.495^{\mathrm{a}, \mathrm{f}}$ \\
\hline & 250 & $5.71 \pm 0.565$ & $7.40 \pm 0.718$ & $36.56 \pm 1.745^{\mathrm{b}, \mathrm{d}}$ & $2.94 \pm 0.501^{\mathrm{b}}$ \\
\hline \multirow[t]{2}{*}{ EEB } & 125 & $7.67 \pm 0.764$ & $5.20 \pm 2.059$ & $23.38 \pm 4.836^{\mathrm{a}, \mathrm{f}}$ & $5.01 \pm 0.515^{\mathrm{a}, \mathrm{d}}$ \\
\hline & 250 & $7.43 \pm 0.841$ & $4.71 \pm 0.808$ & $21.52 \pm 4.937^{\mathrm{c}, \mathrm{e}}$ & $4.46 \pm 0.661^{\mathrm{b}, \mathrm{f}}$ \\
\hline \multirow[t]{2}{*}{$A B$} & 125 & $8.80 \pm 0.416$ & $6.44 \pm 0.904$ & $23.20 \pm 1.533^{\mathrm{c}, \mathrm{e}}$ & $6.11 \pm 0.433^{\mathrm{d}, \mathrm{e}}$ \\
\hline & 250 & $8.81 \pm 0.499$ & $5.06 \pm 1.028$ & $20.02 \pm 3.942^{c, e}$ & $5.66 \pm 0.856^{\mathrm{d}, \mathrm{e}}$ \\
\hline
\end{tabular}

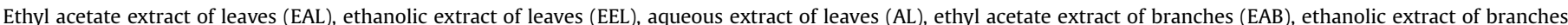

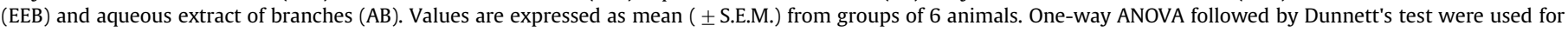
statistical significance.

${ }^{a} P<0.01$, vs. hyperuricemic control group.

${ }^{\mathrm{b}} \mathrm{P}<0.001$, vs. hyperuricemic control group.

c $P<0.05$, vs. normouricemic control group.

${ }^{\mathrm{d}} P<0.001$, vs. normouricemic control group.

e $P<0.05$, vs. hyperuricemic control group.

${ }^{\mathrm{f}} \mathrm{P}<0.01$, vs. normouricemic control group.

extract reduced uric acid to values that did not showed significant differences when compared to normal control group.

\subsection{Uricosuric effects of Pimenta pseudocaryophyllus extracts in hyperuricemic rats}

In general, treatment with $P$. pseudocaryophyllus extracts caused insignificant changes in water intake and urine output of hyperuricemic rats. These data, as well as the extracts effects on uric acid urinary excretion and serum uric acid are shown in Table 2 . The rats became hyperuricemic by a single administration of potassium oxonate intraperitoneally $(200 \mathrm{mg} / \mathrm{kg}$ ) and uric acid orally $(1 \mathrm{~g} / \mathrm{kg})$, showing a higher uric acid excretion when compared to normal control animals. Rats treated with clinically used drugs benzbromarone $(10 \mathrm{mg} / \mathrm{kg})$ and probenecid $(50 \mathrm{mg} / \mathrm{kg})$, as well as EAL, EAB, EEB, AB (125 and $250 \mathrm{mg} / / \mathrm{kg}$ ) and AL (250 mg// $\mathrm{kg}$ ) promoted a significant increase in uric acid excretion when compared to hyperuricemic control animals.

\subsection{In vivo xanthine oxidase inhibitory activity}

Table 3 shows the effect of $P$. pseudocaryophyllus extracts on liver xanthine oxidase residual activity. Hyperuricemia induction did not cause any appreciable changes on liver xanthine oxidase residual activity, since this enzyme is not inhibited during the process of hyperuricemia induction. A single dose of allopurinol $(10 \mathrm{mg} / \mathrm{kg})$ caused a significant reduction (76.14\%) of liver xanthine oxidase residual activity. EEL, EEB, AB (125 and $250 \mathrm{mg} / \mathrm{kg}$ ) and EAB $(250 \mathrm{mg} / \mathrm{kg}$ ) caused a significant inhibition of liver xanthine oxidase residual activity, especially EEL (125 and $250 \mathrm{mg} / \mathrm{kg}$ ), that caused an enzyme inhibition of $45.55 \%$ and $45.16 \%$, respectively.

\subsection{Effects of Pimenta pseudocaryophyllus extracts on MSU-induced inflammation in mice}

The edema observed on animals that received only vehicle after MSU crystals injection was considered as the maximum inflammation. It was used as reference and compared to other treatments in
Table 3

Effects of Pimenta pseudocaryophyllus extracts and allopurinol on xanthine oxidase liver activity from hyperuricemic rats.

\begin{tabular}{llll}
\hline Group & $\begin{array}{l}\text { Dose } \\
(\mathrm{mg} / \mathrm{kg})\end{array}$ & $\begin{array}{l}\text { Xanthine oxidase activity } \\
(\mathrm{nmol} / \mathrm{min} / \mathrm{mg} \text { protein })\end{array}$ & Inhibition $(\%)$ \\
\hline $\begin{array}{l}\text { Normouricemic } \\
\text { control }\end{array}$ & - & $24.34 \pm 2.362$ & - \\
$\begin{array}{c}\text { Hyperuricemic } \\
\text { control }\end{array}$ & - & $28.54 \pm 2.689$ & - \\
Allopurinol & 10 & $6.81 \pm 0.379^{\mathrm{a}}$ & 76.14 \\
EAL & 125 & $27.97 \pm 1.413$ & - \\
& 250 & $29.33 \pm 2.262$ & - \\
EEL & 125 & $15.54 \pm 1.318^{\mathrm{a}}$ & 45.55 \\
& 250 & $15.65 \pm 1.611^{\mathrm{a}}$ & 45.16 \\
AL & 125 & $30.15 \pm 2.767$ & - \\
& 250 & $22.85 \pm 2.284$ & - \\
EAB & 125 & $24.35 \pm 1.271$ & 35.46 \\
& 250 & $18.42 \pm 2.023^{\mathrm{b}}$ & 26.10 \\
EEB & 125 & $21.09 \pm 0.655^{\mathrm{c}}$ & 30.10 \\
& 250 & $19.95 \pm 3.178^{\mathrm{c}}$ & 24.70 \\
AB & 125 & $21.49 \pm 0.873^{\mathrm{c}}$ & 37.70 \\
& 250 & $17.78 \pm 1.750^{\mathrm{b}}$ & \\
\hline
\end{tabular}

Ethyl acetate extract of leaves (EAL), ethanolic extract of leaves (EEL), aqueous extract of leaves $(A L)$, ethyl acetate extract of branches (EAB), ethanolic extract of branches (EEB) and aqueous extract of branches (AB). Values were expressed as mean \pm S.E.M. of six animals. For statistical significance, One-way ANOVA was used followed by Dunnett's test.

a $P<0.001$, vs. hyperuricemic control group.

${ }^{b} P<0.01$, vs. hyperuricemic control group.

${ }^{c} P<0.05$, vs. hyperuricemic control group.

order to evaluate the anti-inflammatory activity (Table 4). Treatments with $\mathrm{AL}$ and $\mathrm{AB}$ were not able to reduce paw edema significantly at any tested dose. EEL (125 and $250 \mathrm{mg} / \mathrm{kg}$ ) and EEB $(250 \mathrm{mg} / \mathrm{kg}$ ) significantly reduced paw edema at $48 \mathrm{th}$ h. Treatment with EAL and EAB were able to reduce edema at all evaluated times. Indomethacin $(3 \mathrm{mg} / \mathrm{kg})$ showed a significant anti-inflammatory activity similarly to that observed on groups treated with ethyl acetate and ethanol extracts from P. pseudocaryophyllus. 
Table 4

Effects of extracts of Pimenta pseudocaryophyllus on MSU crystal-induced paw edema in mice.

\begin{tabular}{lllll}
\hline \multirow{2}{*}{ Group } & Dose $(\mathrm{mg} / \mathrm{kg})$ & \multicolumn{3}{l}{ Thickness variation $\Delta(\mathrm{mm})$} \\
\cline { 3 - 5 } & & $4 \mathrm{~h}$ & $24 \mathrm{~h}$ & $48 \mathrm{~h}$ \\
\cline { 3 - 5 } & & $0.18 \pm 0.038^{\mathrm{a}}$ & $0.16 \pm 0.049^{\mathrm{a}}$ & $0.05 \pm 0.025^{\mathrm{a}}$ \\
Vehicle (salina) & - & $1.72 \pm 0.232$ & $1.48 \pm 0.200$ & $0.92 \pm 0.060$ \\
MSU & - & $0.27 \pm 0.046^{\mathrm{a}}$ & $0.43 \pm 0.091^{\mathrm{a}}$ & $0.32 \pm 0.062^{\mathrm{a}}$ \\
Indomethacin & $\mathbf{3}$ & $0.10 \pm 0.041^{\mathrm{a}}$ & $0.11 \pm 0.081^{\mathrm{a}}$ & $0.13 \pm 0.067^{\mathrm{a}}$ \\
EAL & $\mathbf{1 2 5}$ & $0.30 \pm 0.095^{\mathrm{a}}$ & $0.48 \pm 0.166^{\mathrm{b}}$ & $0.41 \pm 0.164^{\mathrm{a}}$ \\
& $\mathbf{2 5 0}$ & $1.21 \pm 0.209$ & $0.98 \pm 0.189$ & $0.51 \pm 0.078^{\mathrm{b}}$ \\
EEL & $\mathbf{1 2 5}$ & $1.09 \pm 0.277$ & $1.04 \pm 0.131$ & $0.52 \pm 0.130^{\mathrm{c}}$ \\
& $\mathbf{2 5 0}$ & $1.17 \pm 0.240$ & $1.52 \pm 0.154$ & $1.09 \pm 0.176$ \\
$\mathrm{AL}$ & $\mathbf{1 2 5}$ & $1.33 \pm 0.209$ & $0.15 \pm 0.185$ & $0.86 \pm 0.166$ \\
& $\mathbf{2 5 0}$ & $0.20 \pm 0.103^{\mathrm{a}}$ & $1.12 \pm 0.301^{\mathrm{c}}$ & $0.39 \pm 0.053^{\mathrm{a}}$ \\
EAB & $\mathbf{1 2 5}$ & $0.27 \pm 0.129{ }^{\mathrm{a}}$ & $0.51 \pm 0.131^{\mathrm{a}}$ & $0.26 \pm 0.097^{\mathrm{a}}$ \\
& $\mathbf{2 5 0}$ & $1.63 \pm 0.095$ & $1.40 \pm 0.265$ & $0.76 \pm 0.128$ \\
EEB & $\mathbf{1 2 5}$ & $1.12 \pm 0.195$ & $1.08 \pm 0.222$ & $0.46 \pm 0.127^{\mathrm{a}}$ \\
& $\mathbf{2 5 0}$ & $1.54 \pm 0.078$ & $1.32 \pm 0.187$ & $1.17 \pm 0.166$ \\
AB & $\mathbf{1 2 5}$ & $1.06 \pm 0.079$ & $1.15 \pm 0.118$ & $0.75 \pm 0.033$ \\
& $\mathbf{2 5 0}$ & & &
\end{tabular}

Ethyl acetate extract of leaves (EAL), ethanolic extract of leaves (EEL), aqueous extract of leaves (AL), ethyl acetate extract of branches (EAB), ethanolic extract of branches (EEB) and aqueous extract of branches (AB). Values were expressed as mean \pm S.E.M. of six animals. For statistical significance, One-way ANOVA was used followed by Dunnett's test.

${ }^{a} P<0.001$, vs. paw swelling after MSU crystals injection in vehicle-treated mice.

${ }^{\mathrm{b}} P<0.01$, vs. paw swelling after MSU crystals injection in vehicle-treated mice.

${ }^{c} P<0.05$, vs. paw swelling after MSU crystals injection in vehicle-treated mice.

\section{Discussion}

Hyperuricemia is a metabolic disorder associated with the development of pathological conditions such as gout. The relationship between hyperuricemia and the pathogenesis of gout has been reported since the early nineteenth century (Neogi, 2011). Although the disease afflicts humans for years, there is a limited number of drugs currently used in clinical practice for treating hyperuricemia or gout, which are divided into two classes: xanthine oxidase inhibitors, e.g., allopurinol; and uricosuric agents, for example probenecid and benzbromarone (Murugaiyah and Chan, 2009). Allopurinol is effective in chronic treatments but there are problems associated with its use, as rash, fever, renal, liver and kidney diseases, for instance (Haidari et al., 2009). Uricosuric agents are used in underexcreters patients or in case of allopurinol-allergic syndromes. However, uricosuric agents can also cause problems, as well as they should not be used in patients with history of urolithiasis. In short, benzbromarone can cause fulminant hepatotoxicity, whereas probenecid and sulfinpyrazone have been reported to be nephrotoxic when used to treat hyperuricemia associated with moderate chronic renal insufficiency (Yu et al., 2006).

A potential source of novel anti-hyperuricemic agents may be derived from natural products. The methanol extract and lignans of Phyllanthus niruri showed anti-hyperuricemic effects, the methanol extract activity was assigned to its uricosuric action and partly through xanthine oxidase inhibition, whereas the activity of the lignans was attributed to their uricosuric action (Murugaiyah and Chan, 2009). In previous studies, Lychnophora trichocarpha and Sparattosperma leucanthum proved to be a promise for the treatment of gouty arthritis and hyperuricemia, showing the ability to inhibit hepatic xanthine oxidase and anti-inflammatory activity (De Souza et al., 2012; Lima et al., 2015).

In the present study, the specie P. pseudocaryophyllus was able to expressively inhibit xanthine oxidase in vitro. It has been previously reported that plant extracts causing more than $50 \%$ of enzyme inhibition at a test concentration of $50 \mu \mathrm{g} / \mathrm{mL}$ justifies further investigations (Schmeda-Hirschmann et al., 1996). As all extracts (except $A L$ and $A B$ ) showed $\mathrm{IC}_{50}$ values under $50 \mu \mathrm{g} / \mathrm{mL}$, they were in vivo evaluated.

Administration of $P$. pseudocaryophyllus extracts from leaves and branches caused a reduction in serum uric acid levels in hyperuricemic rats. This fact can be understood through the two pathways investigated. The extracts EAL, EAB, EEB and AB two evaluated doses and $\mathrm{AL},(250 \mathrm{mg} / \mathrm{kg})$ showed an increased urinary excretion of uric acid. It is estimated that $80-90 \%$ of patients with gout are underexcreters (Rott and Agudelo, 2003), indicating the importance of uricosuric action as a therapeutic target. EEL, EAB, EEB and AB were able to inhibit the residual activity of liver xanthine oxidase. Thus, $P$. pseudocaryophyllus extracts were able to reduce hyperuricemia through the two investigated pathways: increasing uric acid urinary excretion and inhibiting liver xanthine oxidase.

Inflammation is one of the major problems reported on gout patients and this relationship has been evaluated using in vitro studies, animal and human models (Krishnan, 2014). One of the main characteristics of acute gouty arthritis is the cell activation promoted by monosodium urate (MSU) microcrystals in joints, which can interact with cells such as neutrophils, monocytes, macrophages and synovial cells as fibroblasts (Jiang et al., 2012). For example, in monocytes, microcrystals stimulate the synthesis of a large number of pro-inflammatory cytokines such as tumor necrosis factor (TNF- $\alpha$ ), IL-1 $\beta$, IL-6 and IL-8 (Neogi, 2011). In addition, macrophages phagocyte urate crystals initiating the release of lysosomal enzymes involved in processes such as chemotaxis and cell permeability (Rasool and Varalakshmi, 2006). In the present study, it was observed that the ethyl acetate extracts (EAL and $\mathrm{EAB}$ ) showed significant reduction in paw edema induced by MSU crystals at $4 \mathrm{~h}, 24 \mathrm{~h}$ and $48 \mathrm{~h}$. These extracts also increased urinary excretion of uric acid (EAL and EAB) and inhibited liver xanthine oxidase (EAB $250 \mathrm{mg} / \mathrm{kg}$ ), indicating a synergistic action that may represent efficacy in the treatment of gout and hyperuricemia.

Previous phytochemical investigations of $P$. pseudocaryophyllus resulted in the isolation of the pentacyclic triterpenes lupeol, $\alpha$ amyrin, and $\beta$-amyrin and the flavonoids quercetin, quercitrin, and afzelin (Paula et al., 2012). Among these compounds, lupeol and quercetin have reports of reducing uric acid levels in hyperuricemic mice caused by oxonate. The hypouricemic effects of quercetin is partly due to inhibition of liver xanthine oxidase residual activity (Zhu et al., 2004). Lupeol does not have its hypouricemic mechanism described (De Souza et al., 2012).

These compounds are also related to anti-inflammatory activity. Quercetin also inhibited the inflammatory response induced by carrageenan in rats. The contents of $\mathrm{PGE}_{2}$, TNF- $\alpha$, RANTES, MIP- 2 and the mRNA for cyclooxygenase-2 were suppressed in these rats (Morikawa, et al., 2003). Lupeol have inhibitory properties on the production of inflammatory cytokines as IL-1, TNF- $\alpha$ and PGE $_{2}$ release by macrophages in vitro (Fernández et al., 2001). The pentacyclic triterpene $\alpha$-amyrin exhibits strong and rapid anti-inflammatory actions in the mouse ear edema induced by 12-O-tetradecanoylphorbol-13acetate (TPA). The mechanism seems to involve its ability to inhibit the levels of $\mathrm{PGE}_{2}$, via inhibition of the COX-2 expression (Medeiros et al., 2007). The administration of $\beta$-amyrin caused a significant decrease in carrageenan-induced paw edema in a dose-dependent manner. Treatment with $\beta$-amyrin significantly inhibited $\mathrm{PGE}_{2}$, IL-6 secretion and NF- $\kappa B$ activation in a concentration-dependent manner on LPS induced (Krishnan et al., 2014).

Thus, anti-hyperuricemic effects by uricosuric or inhibition of xanthine oxidase way and anti-inflammatory activity presented by the P. pseudocaryophyllus extracts can be partially attributed to these compounds. 


\section{Conclusions}

The specie $P$. pseudocaryophyllus showed remarkable anti-hyperuricemic activity. The tested extracts were able to reduce serum uric acid through the two main pathways of uric acid regulation in human body, by inhibiting its formation and increasing its excretion. Therefore, $P$. pseudocaryophyllus extracts can be considered promising in the treatment of diseases related to hyperuricemia. Moreover, ethyl acetate extracts also had significant antiinflammatory activity.

Several flavonoids have shown the ability to inhibit xanthine oxidase, anti-hyperuricemic and anti-inflammatory activities. Flavonoids were detected in all evaluated extracts, being considered the predominant metabolites in P. pseudocaryophyllus. Therefore, this group of metabolites may be responsible for the anti-hyperuricemic and anti-inflammatory effects of $P$. pseudocaryophyllus extracts. However, only a full elucidation of the specie chemical profile will highlight the active substances.

\section{Acknowledgments}

The authors would like to thank FAPEMIG (Fundação de Amparo à Pesquisa do Estado de Minas Gerais) CDS APQ-00956-13, REDE TOXIFAR/FAPEMIG (Rede Mineira de Ensaios Toxicológicos e Farmacológicos/Fundação de Amparo à Pesquisa de Minas Gerais) RED 00008/14, CAPES (Coordenação de Aperfeiçoamento de Pessoal de Nível Superior) and UFOP (Universidade Federal de Ouro Preto) for financial support. CAPES funded PhD scholarships of Fernanda Ferrari and Marcela Araújo.

\section{References}

Albrecht, E., Waldenberger, M., Krumsiek, J., Evans, A.M., Jeratsch, U., Breier, M., Adamski, M., Koenig, W., Zeilinger, S., Fuchs, C., Klopp, N., Theis, F.J., Wichmann, H.-E., Suhre, K., Illig, T., Strauch, K., Peters, A., Gieger, C., Kastenmüller, G., Doering, A., Meisinger, C., 2014. Metabolite profiling reveals new insights into the regulation of serum urate in humans. Metabolomics 10, 141-151.

Bradford, M.M., 1976. A rapid and sensitive method for the quantification of microgram quantities of protein utilizing the principle of protein-dye binding. Anal. Biochem. 72, 248-254.

Campanini, M.Z., Custódio, D.L., Ivan, A.L.M., Martins, S.M., Paranzini, M.J.R., Martinez, R.M., Verri, W.A.J., Vicentini, F.T.M.C., Arakawa, N.S., Faria, T.J., Baracat, M. M. Casagrande, R. Georgetti, S.R, 2014. Topical formulations containing Pimenta pseudocaryophyllus extract: in vitro antioxidant activity and in vivo efficacy against UV-B-induced oxidative stress. AAPS PharmSciTech 15, 86-95.

D’Angelis, A.S.R., Negrelle, R.R.B., 2014. Pimenta pseudocaryophyllus (Gomes) Landrum: aspectos botânicos, ecológicos, etnobotânicos e farmacológicos. Rev. Bras. Plantas Med. 16, 607-617.

De Souza, M.R., Paula, C.A., Resende, M.L.P., Grabe-Guimarães, A., Filho, J.D.S., Saúde-Guimarães, D.A., 2012. Pharmacological basis for use of Lychnophora trichocarpha in gouty arthritis: anti-hyperuricemic and anti-inflammatory effects of its extract, fraction and constituents. J. Ethnopharmacol. 142, 845-850.

Fajemiroye, J.O., Martins, J.L.R., Brito, A.F., Galdino, P.M., Paula, J.R., Paula, J.A.M.,
Costa, E.A., 2012. Central activities of Pimenta pseudocaryophyllus (Gomes) L.R. Landrum. Int. J. Med. Arom. Plants 2, 118-122.

Farnsworth, N.R., 1966. Biological and phytochemical screening of plants. J. Pharm. Sci. 55, 225.

Fernández, M.A., De Las Heras, B., Garcia, M.D., Saenz, M.T., Villar, A., 2001. New insights into the mechanism of action of the anti-inflammatory triterpene lupeol. J. Pharm. Pharmacol. 53, 1533-1539.

Ferraz Filha, Z.S., Vitolo, I.F., Fietto, L.G., Lombardi, J.A., Saúde Guimarães, D.A., 2006 Xanthine oxidase inhibitory activity of Lychnophora species from Brazil ("Arnica"). J. Ethnopharmacol. 107, 79-82.

Haidari, F., Keshavarz, A.S., Reza Rashidi, R.M., Shahi, M.M., 2009. Orange juice and hesperetin supplementation to hyperuricemic rats alter oxidative stress markers and xanthine oxidoreductase activity. J. Clin. Biochem. Nutr. 45, 285-291.

Hall, I.H., Scoville, J.P., Reynolds, D.J., Simlot, R., Duncan, P., 1990. Substituted cyclic imides as potencial anti-gout agents. Life Sci. 46, 1923-1927.

Jiang, Y., You, X.-Y., Fu, K.-L., Yin, W.-L., 2012. Effects of extract from Mangifera indica leaf on monosodium urate crystal-induced gouty arthritis in rats. BMC Complement. Altern. Med. 2012, 1-6.

Krishnan, E. 2014. Interaction of inflammation, hyperuricemia, and the prevalence of hypertension among adults free of metabolic syndrome: NHANES 20092010. J. Am. Heart Assoc. 3 (2), 1-10.

Krishnan, K., Mathew, L.E., Vijayalakshmi, N.R., Helen, A., 2014. Anti-inflammatory potential of $\beta$-amyrin, a triterpenoid isolated from Costus igneus. Inflammopharmacology 22, 373-385.

Lima, R.C.L., Ferrari, F.C., De Souza, M.R., Pereira, B.M.S., De Paula, C.A., Saúde-Guimarães, D.A., 2015. Effects of extracts of leaves from Sparattosperma leucanthum on hyperuricemia and gouty arthritis. J. Ethnopharmacol. 161, 194-199.

Matos, F.J.A., 1997. Introdução à Fitoquímica Experimental, 2nd ed. Edições UFC, Fortaleza.

Medeiros, R., Otuki, M.F., Avellar, M.C., Calixto, J.B., 2007. Mechanisms underlying the inhibitory actions of the pentacyclic triterpene $\alpha$-amyrin in the mouse skin inflammation induced by phorbol ester 12-0-tetradecanoylphorbol-13-acetate. Eur. J. Pharmacol. 559, 227-235.

Miguel, C., Mediavilla, M.J., 2011. Abordagem actual da gota. Acta Med. Port. 24, $791-798$.

Morikawa, K., Nonaka, M., Narahara, M., Torii, I., Kawaguchi, K., Yoshikawa, T., Kumazawa, Y., Morikawa, S., 2003. Inhibitory effect of quercetin on carrageenaninduced inflammation in rats. Life Sci. 74, 709-772.

Murugaiyah, V., Chan, K.-L., 2009. Mechanisms of anti-hyperuricemic effect of Phyllanthus niruri and its lignin constituents. J. Ethnopharmacol. 124, 233-239.

Neogi, T., 2011. Clinical practice. Gout. N. Engl. J. Med. 364, 443-452.

National Institutes of Health, 1985. Guide for the Care and Use of Laboratory Animals Public Health Service. NIH Publication, Bethesda, NIH.

Paula, J.A.M., Silva, M.R.R., Costa, M.P., Diniz, D.G.A., Sá, F.A.S., Alves, S.F., Costa, E.A. Lino, R.C., Paula, J.R., 2012. Phytochemical analysis and antimicrobial, antinociceptive, and anti-inflammatory activities of two chemotypes of Pimenta pseudocaryophyllus (Myrtaceae). BMC Complement. Altern. Med. 2012, 1-15.

Pinheiro, G.R.C., 2008. Diet Orientation on Gout Revisited. Rev. Bras. Reum. 48, $157-161$.

Rasool, M., Varalakshmi, P., 2006. Suppressive effect of Withania somnifera root powder on experimental gouty arthritis: an in vivo and in vitro study. Chem. Biol. Interact. 164 (3), 174-180.

Rott, K.T., Agudelo, C.A., 2003. Gout. J. Am. Med. Assoc. 289, 2857-2860.

Schmeda-Hirschmann, G., Zuniga, J., Dutra-Behrens, M., Habermehl, G., 1996. Xanthine oxidase inhibitory activity of flavonoids and tannins from Hexachlamys edulis (Myrtaceae). Phytother. Res. 10, 260-262.

Smith, E.U.R., Diaz-Torne, C., Perez-Ruiz, F., March, L.M., 2010. Epidemiology of gout: an update. Best. Pract. Res. 24, 811-827.

Yu, Z., Fong, W.P., Cheng, C.H.K., 2006. The dual actions of morin (3,5,7,2,4-pentahydroxyflavone) as a hypouricemic agent: uricosuric effect and xanthine oxidase inhibitory activity. J. Pharmacol. Exp. Ther. 316, 169-175.

Zhu, J.X., Wang, Y., Kong, L.D., Yang, C., Zhang, X., 2004. Effects of Biota orientalis extract and its flavonoid constituents, quercetin and rutin on serum uric acid levels in oxonate-induced mice and xanthine dehydrogenase and xanthine oxidase activities in mouse liver. J. Ethnopharmacol. 93, 133-140. 